\title{
Note on TrANSLITERATION AND REFERENCING
}

I have transcribed all uses of Thai terms in accordance with the Royal Thai General System of Transcription using the transcription tool provided by the online dictionary Thai-language.com. There are notable exceptions: I deploy conventional spellings of well-known people-for instance, King Vajiravudh instead of Wachirawut; moreover, when transcribing personal and family names I have followed, when known, the preferences of those individuals.

Following Thai studies conventions, Thai authors are referred to by their given names, not surnames; in accordance, all citations by Thai authors are alphabetized in the bibliography and elsewhere by given names. 


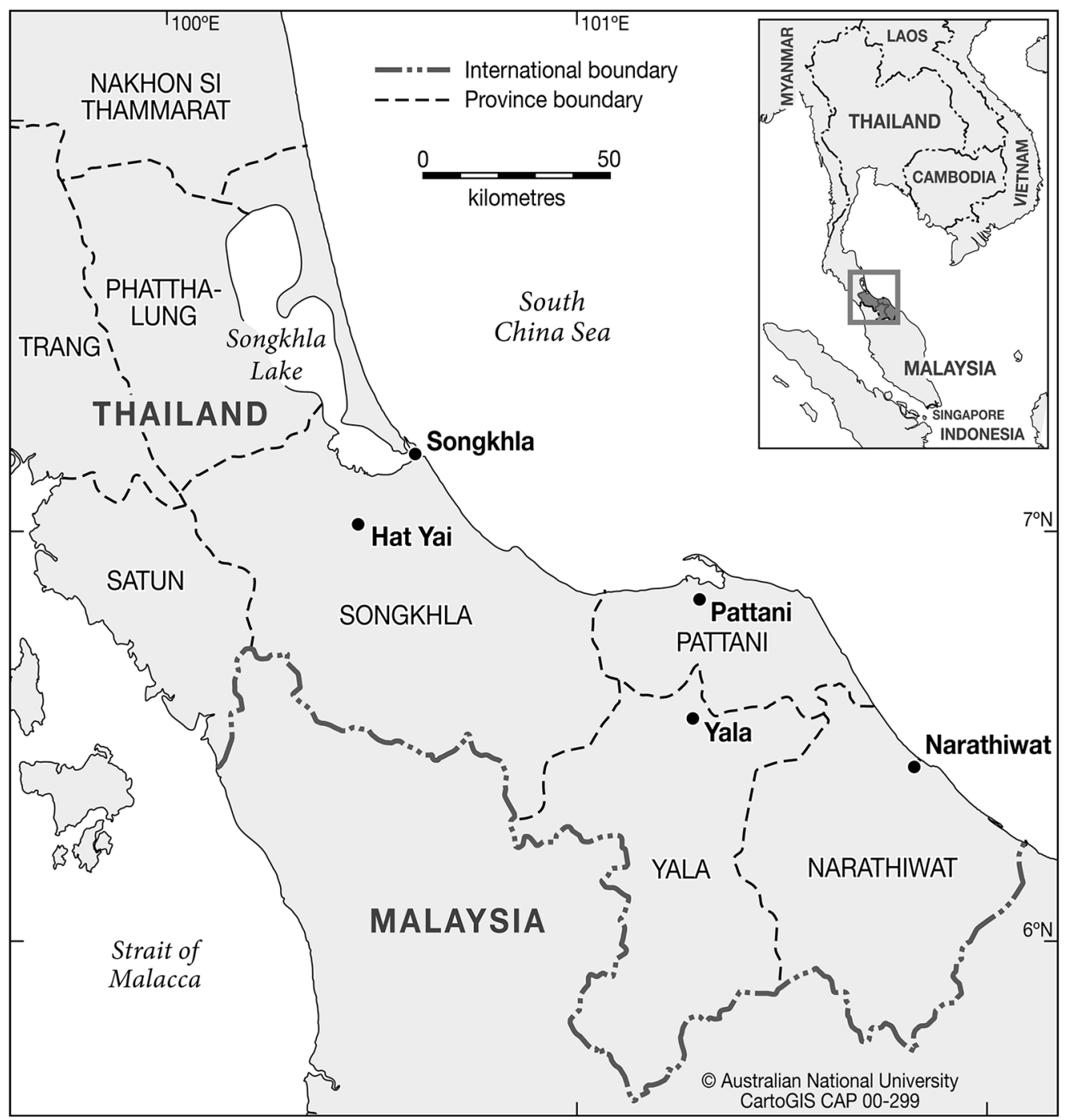

Figure 1. Map of Thailand's southern border provinces. Source: The Australian National University, College of Asia and the Pacific, CartoGIS Services. 


\section{Uneasy Military Encounters}


